\title{
Advances in the T7 phage display system (Review)
}

\author{
XIANGYING DENG $^{1,2}$, LI WANG $^{1}$, XIAOLONG YOU $^{1}$, PEI DAI $^{1}$ and YANHUA ZENG ${ }^{1}$ \\ ${ }^{1}$ Institute of Pathogenic Biology, Medical College, University of South China, Hunan Provincial Key Laboratory for \\ Special Pathogens Prevention and Control, Hunan Province Cooperative Innovation Center for Molecular Target \\ New Drug Study, Hengyang, Hunan 421001; ${ }^{2}$ The Key Laboratory of Carcinogenesis and Cancer Invasion of
}

The Chinese Ministry of Education, Cancer Research Institute, Central South University, Changsha, Hunan 410078, P.R. China

Received February 12, 2017; Accepted August 10, 2017

DOI: $10.3892 / \mathrm{mmr} .2017 .7994$

\begin{abstract}
The present review describes the advantages and updated applications of the T7 phage display system in bioscience and medical science. Current phage display systems are based on various bacteriophage vectors, including M13, T7, T4 and f1. Of these, the M13 phage display is the most frequently used, however, the present review highlights the advantages of the T7 system. As a phage display platform, M13 contains single-stranded DNA, while the T7 phage consists of double-stranded DNA, which exhibits increased stability and is less prone to mutation during replication. Additional characteristics of the T7 phage include the following: The $\mathrm{T} 7$ phage does not depend on a protein secretion pathway in the lytic cycle; expressed peptides and proteins are usually located on the C-terminal region of capsid protein gp10B, which avoids problems associated with steric hindrance; and T7 phage particles exhibit high stability under various extreme conditions, including high temperature and low $\mathrm{pH}$, which facilitates effective high-throughput affinity elutriation. Recent applications of the T7 phage display system have been instrumental in uncovering mechanisms of molecular interaction, particularly in the fields of antigen discovery, vaccine development, protein interaction, and cancer diagnosis and treatment.
\end{abstract}

\section{Contents}

1. Introduction

2. T7 bacteriophage: Structure and biological properties

3. The advantages of $\mathrm{T} 7$ phage display system

4. Applications of T7 phage display system

5. Conclusions and further perspectives

Correspondence to: Professor Yanhua Zeng, Institute of Pathogenic Biology, Medical College, University of South China, Hunan Provincial Key Laboratory for Special Pathogens Prevention and Control, Hunan Province Cooperative Innovation Center for Molecular Target New Drug Study, 28 West Changsheng Road, Hengyang, Hunan 421001, P.R. China

E-mail: zengyihua21cn@126.com

Key words: $\mathrm{T} 7$ phage, $\mathrm{T} 7$ phage display, protein interaction, antigen discovery, vaccine development, cancer diagnosis and treatment

\section{Introduction}

In 1985, George Smith was the first to employ a phage display system (1). He expressed, by inserting exogenous DNA into phage gene III, various foreign peptides on the capsid of the filamentous bacteriophage $\mathrm{f} 1$. Peptides and proteins of interest were obtained from a library of random insert genes in a phage display vector by $\geq 1$ rounds of selection, thus facilitating the analysis of associations between genotype and phenotype (1). The common principle of all phage display systems is that exogenous peptide-coding sequences are inserted into a phage capsid protein gene, which allows the expression of foreign proteins or peptides fused to the capsid protein of the phage particle (2-4). Exogenous peptides or proteins of interest are subsequently selected from a large library of phage particles by techniques such as affinity elutriation $(5,6)$. Phage display systems are an efficient and rapid tool in the investigation of protein sequences and have also been particularly important in proteomics.

Numerous bacteriophage species have been employed in phage display systems, including f1, fd, T4, M13 and T7, of which the latter two examples are considered to be efficient display vectors. The most commonly employed phage display system is M13 as it contains nonessential regions that allow exogenous gene insertions. Exogenous peptides, retaining their normal function, are expressed in the M13 coat proteins $(7,8)$ and the phage retains the ability to accumulate at high concentrations in hosts. Although a few of peptide repertoires successfully expressed in a cDNA library of filamentous phage $(9,10)$, M13 phage display is associated with limitations in the construction of the cDNA library. The formation of fusion proteins consisting of the coat proteins and the expressed peptides, and the secretion of phage into the periplasm, are also potential problems in M13 phage display. However, these problems associated with M13 phage display may be avoided by using the T7 phage display system.

Rapid development in the research of pathogenic microorganisms and proteomics has been achieved through use of the T7 phage display system. Various virus vaccines, such as those against influenza virus and hepatitis B virus, require frequent development, and the methods of diagnosis and treatment of infectious diseases also require continuous improvement. By using a T7 phage display library, one study identified the mechanism underlying the anti-inflammatory 
effect of hydrostatin-SN1, a peptide present in the venom gland of Hydrophis cyanocinctus (11). In addition, a reconstructive T7 phage combined with a magnetic separation technique was applied for the detection of viable bacterial cells (12). The favorable characteristics of the $\mathrm{T} 7$ phage result in a wide range of potential applications. The present study primarily describes the structure and biological properties of the $\mathrm{T} 7$ phage and its application through phage display system to various research areas, including the mechanism of protein interactions in biology, the discovery of novel pathogenic antigens, vaccine development, and cancer diagnosis and therapy.

\section{T7 bacteriophage: Structure and biological properties}

Bacteriophage T7 was defined in 1945 as one of the seven phages that replicate in $E$. coli (13). The DNA of the T7 phage is $40 \mathrm{~kb}$ and is packed into the $60 \mathrm{~nm}$ diameter cavity formed by the capsid protein. The capsid, or head, is the outer protective shell of the phage, which protects the viral nucleic acid The phage particle consists of the following six major proteins: gp10A (primary capsid protein); gp10B (secondary capsid protein); gp8 (connector); gp11 and gp12 (tail proteins); and gp17 (tail fiber). The majority of the capsid protein is made up of gp10, which includes gp10A (344 amino acids) and gp10B (397 amino acids). Gp10A and gp10B are products of gene 10 and are expressed at a ratio of 9:1 under normal conditions. Gp10B is the result of a frame shift at the end of the gp10A coding frame (14). Foreign proteins or peptides are fused to the C-terminus of gp10B $(14,15)$. The proportion of gp10A and gp10B may vary according to conditions; however, this does not affect the activity of the phage (15).

A diagram of the structure of the $\mathrm{T} 7$ phage is presented in Fig. 1, which highlights the connector between the head and tail. The connector is a ring structure that consists of multiple copies of gp8. Inside the head, the core of the T7 phage forms a cylindrical structure and this combines with gp8 to connect the head and tail. Gp15, gp14 and gp16 may form a pathway across the outer membrane of cells following the initial step of infection bacteria (16).

T7 adsorption to lipopolysaccharide on the cell surface may be similar to the T4 adsorption process (17), however, it is more difficult for the T7 DNA to directly enter the cytoplasm of bacteria from the adsorption position. Therefore, in order to insert T7 DNA into bacteria, a tubular structure that traverses the outer membrane of bacteria is required. Cooperation between gp15 and gp16 completes the process of T7 DNA entry into the bacteria (18). The details of this process are fully elucidated (19), and the glycoproteins gp16 and gp15 are key factors in the transfer of T7 DNA to bacteria. The main function of the spiral ring formed by gp15 and gp16 is assisting T7 phage DNA into host bacteria (19).

\section{The advantages of $\mathrm{T} 7$ phage display system}

T7 phage display libraries are formed of numerous phages that carry different exogenous genes and express different peptides on the surface of the phage shell. The amplification of phages that carry these exogenous genes leads to the replication of the foreign peptide in the library, which allows a large amount of the identical exogenous peptide to be expressed on progeny phage. In vivo and in vitro applications of the $\mathrm{T} 7$ phage display system exist (20), however, the majority of applications are currently in vitro. The construction of $\mathrm{T} 7$ phage display libraries is associated with advantages that include easy accessibility and few equipment requirements (21).

Phage display systems usually employ filamentous phages, including M13, fd, and f1 (22). However, these vectors are associated with a limited cloning capacity, which in the case of M13 is $<1,500 \mathrm{bp}$, and their genome exhibits markedly reduced stability following insertion of foreign DNA. By contrast, recombinant $\mathrm{T} 7$ is very stable, even with foreign gene inserts $>1 \mathrm{~kb}$. Compared with M13, advantages of T7 as a phage display vector include the following: T7 grows quickly and forms plaques within $3 \mathrm{~h}$, which saves time during cloning and screening (23), while M13 grows slowly; the construction of large display libraries is easier in T7 compared with M13; unlike filamentous phagemids, foreign cDNA library is directly inserted into $\mathrm{T} 7$ phage genome and expressed as capsid fusion proteins; various types of cDNA libraries may be constructed using T7 phage as a vector $(23,24)$; affinity elutriation, which is employed to select the proteins or peptides of interest in the display library, is efficient and effective with T7; and with T7, the likelihood of survival of the recombinant phage in the environment is reduced, as the host cell is required to produce $\mathrm{T} 7$ gene 10 to express proteins.

\section{Applications of T7 phage display system}

T7 phage display system for antigen and epitope discovery. The discovery of antigen, surface antigen on pathogenic microorganisms and cancer antigens, may be achieved using the T7 phage display system. Various studies have demonstrated the power of $\mathrm{T} 7$ phage display on the discovery of antigens $(25,26)$. For example, a T7 phage display cDNA library was constructed from cell mRNA of bronchoalveolar lavage in the granulomatous inflammatory disease, sarcoidosis, which led to the identification of 1152 potential sarcoidosis antigens (27). The discovery of useful antigens in epidemic diseases, such as influenza and tuberculosis, will aid the diagnosis and treatment of these diseases. The ectodomain of influenza A virus M2 protein, which may be expressed on the surface of the T7 phage, provides immunoprotection against influenza A (28). Recent studies from our laboratory involved the construction of a Mycobacterium tuberculosis genomic library using T7 phage as a carrier, which was subsequently screened for the dominant $M$. tuberculosis antigen recognized in the serum of patients with tuberculosis (Yanhua Zeng et al, unpublished data).

In addition, phage peptide libraries allow the rapid determination of the sequence of protein epitopes, and have become a powerful tool for investigating the interaction between epitopes and antigen receptors. At present, studies have employed phage display to identify epitopes for human immunodeficiency virus (HIV) (29), hepatitis C virus (30), West Nile virus (31), Mycoplasma pneumoniae (32), Streptococcus pneumoniae (33), Helicobacter pylori (34) and streptococcus disease pathogens in pigs (35). The VP1 epitope displayed by $\mathrm{T} 7$ phage may be used as a potential diagnostic reagent in foot-and-mouth disease (36). In addition, an immunodominant epitope that originated from the rat erb-b2 


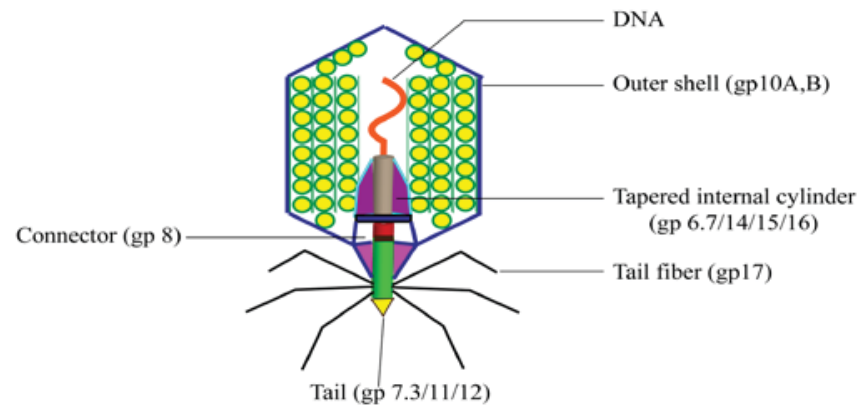

Figure 1. Detailed structure of T7 phage. The genetic material of the T7 phage is linear double-stranded DNA. The primary function of the outer shell, which is termed the capsid and consists predominantly of gp10A and gp10B, is to protect the DNA. The injection of DNA into the host cel requires the presence of a tapered internal cylinder. The primary role of the tail fiber is to fix the $\mathrm{T} 7$ phage onto the surface of host cell during the process of adsorption; if the tail is too short, it cannot puncture the outer membrane of the host cell. The connector is a ring structure that consists of multiple copies of gp8 and connects the head and tail.

receptor tyrosine kinase 2 (HER-2/neu) oncoprotein was expressed by $\mathrm{T} 7$ bacteriophage nanoparticles. The induction of robust cytotoxic T lymphocyte (CTL) responses indicated that T7 phage nanoparticles offer higher levels of immunogenicity on the HER-2-derived minimal CTL epitope (37). Therefore, these results indicate that phage display, particularly the T7 phage display system, may be a powerful tool for antigen discovery and epitope identification.

T7 phage display system for the investigation of molecule interactions. Protein interaction has a major role in numerous biological processes. The primary process of the identification of small peptides or proteins is by using the corresponding ligands or receptors as molecular targets to search phage display libraries. The proteins that interact with a novel mineralocorticoid receptor (MR) were identified by employing T7 phage display (38). To identify proteins that interact with MR, researchers, using MR as bait, screened T7 phage cDNA libraries derived from either human heart or kidney RNA (38). The results identified 23 non-redundant peptides obtained from the heart library and 7 from the kidney library. In addition, a T7 phage display cDNA library based on N2a cells was constructed and the library was screened with soluble porcine hemagglutinating encephalomyelitis coronavirus (PHE-CoV) glycoproteins. The results identified a novel interaction between neural cell adhesion molecule and $\mathrm{PHE}-\mathrm{CoV}$ spike protein, and this association proved to be critical during PHE-CoV infection (39). Obesity leads to a variety of consequences for a large number of individuals. An improved screening system based on T7 phage display was reported to be an efficient method for identifying tubby-binding proteins (40), which may lead to improvements in the understanding of the mechanisms in obesity. Furthermore, a novel coregulator, SH3 and SYLF domain-containing 1 , which interacts with the androgen receptor was identified using $\mathrm{T} 7$ phage display (41). These studies demonstrate the practicability of $\mathrm{T} 7$ phage display on the identification of ligands or receptors. In addition, the use of T7 phage display libraries with drugs has allowed researchers to investigate interactions between peptides expressed on the surface of phages and drugs. Etoposide functions as an antitumor agent, and E2F transcription factor 4 was demonstrated to be an etoposide-binding protein through T7 phage display (42). Furthermore, T7 phage display may also be performed to investigate the associated mechanisms of host interaction with pathogenic microorganisms. For example, the mechanism of the interactions between certain pathogenic microorganisms and hosts was explored using T7 cDNA display, and it has been hypothesized that the peptides identified in such studies may be useful for pathogen detection and identification $(43,44)$. To improve the understanding of the molecular pathogenesis of gastrointestinal anthrax, one study employed T7 phage display based on the human stomach to identify the proteins that interact with anthrax lethal factor (45). Additionally, by using T7 phage displays, another study identified the inhibitory peptides that exhibited anti-endotoxin activity in vivo and in vitro (46). More recently, our own research group constructed a cDNA library from human urothelium cell RNA using T7 phage as a carrier and screened for receptors of Mycoplasma genitalium adhesion protein (Daipei et al, unpublished data). The results of the above studies demonstrate the value of $\mathrm{T} 7$ phage display system for the investigation of the interactions between molecules, particularly with regards to protein interaction. With further improvements in the technology, we anticipate that the T7 phage display system may have a central role in proteomics research.

T7 phage display system for vaccine development. Phage display systems, including the $\mathrm{T} 7$ phage display system, have been widely used in prophylactic vaccine and therapeutic vaccine development due to a number of advantages, which include simplicity, high levels of safety and stability, and ease of storage and transport (47).

Prophylactic vaccines. The T7 phage display system aids the development of novel vaccines. A sequence encoding the immunodominant region of small hepatitis B virus surface antigen was inserted into the DNA of T7 phage, and the peptide (111-156 amino acids) that was expressed on the surface of the T7 phage induced antigenicity and immunogenicity (48). In addition, the T7 phage display system has been employed in research concerning foot and mouth disease (FMD), which is a highly contagious disease during childhood. The immunodominant region of the capsid protein VP1 of the FMD virus was displayed on the T7 phage capsid surface, which may aid research and the development of a vaccine for FMD (36). At present, an effective vaccine for the prevention of neosporosis is not available. However, one study employed T7 phage display to identify the host cell binding protein that interacts with neosporosis, and this binding protein induced partial immunological protection against neosporosis in mice, which indicates its potential as a candidate vaccine (49). The results of these studies highlight the potential of $\mathrm{T} 7$ phage display in the development of preventative vaccines.

Therapeutic vaccines. Although single-chain variable fragment antibodies (ScFvs) are extremely useful, they are often unstable and difficult to express individually in bacteria. These limitations may avoid through T7 phage display single antibody library technology. ScFvs exert a positive effect 


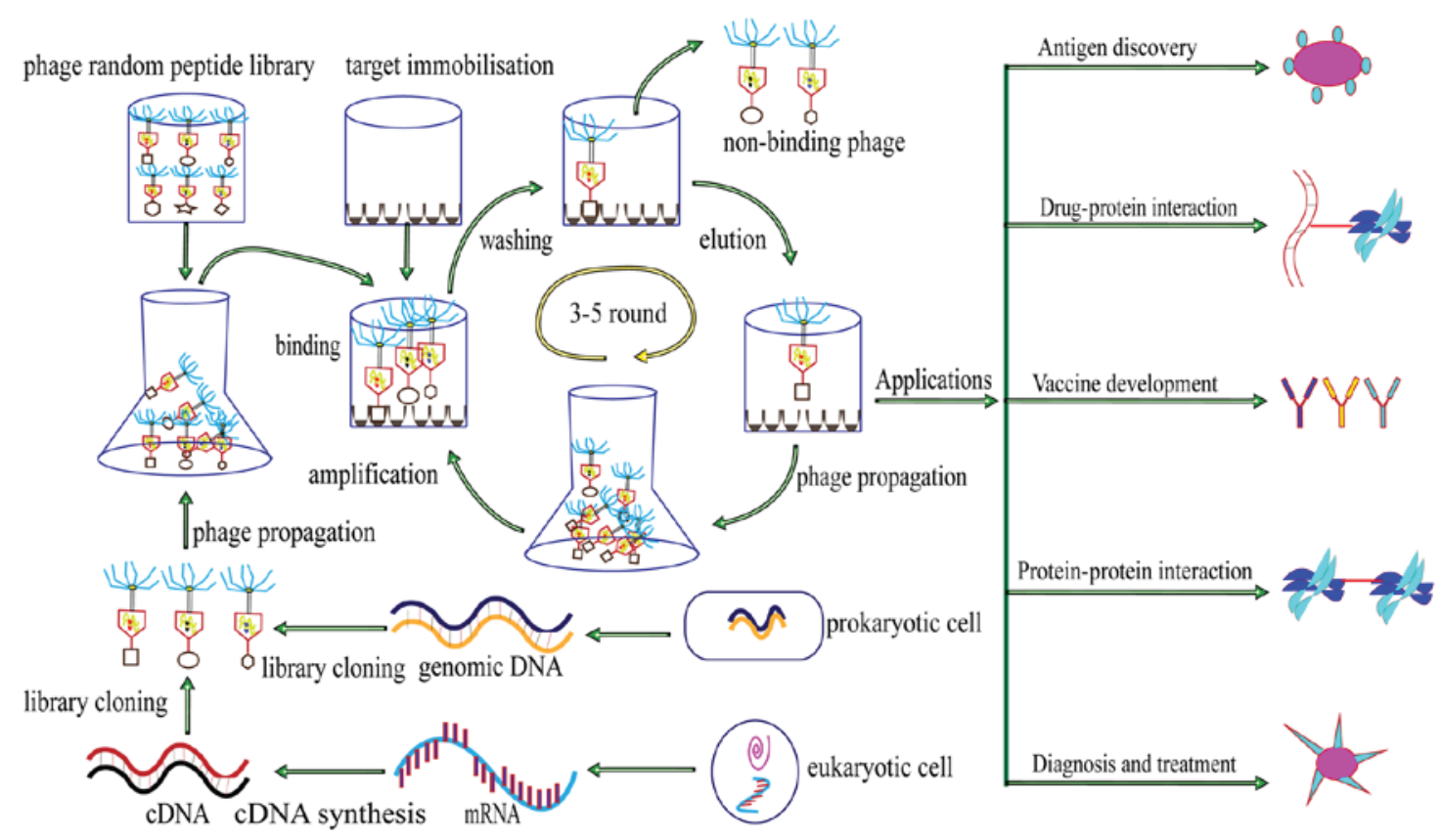

Figure 2. The principle, process and application of T7 phage display libraries. T7 phage display random peptide libraries, genomic DNA libraries constructed from prokaryotic cells or cDNA libraries constructed from eukaryotic cells are propagated and subsequently probed with immobilized target molecules. Non-binding bacteriophages are washed away, and phages that bind specifically with target molecules are eluted and harvested by 3-5 rounds of panning. The T7 phage display system may be performed for antigen discovery, the identification of DNA-protein and protein-protein interactions, vaccine development, and disease diagnosis and treatment.

on the prevention and treatment of a variety of diseases, including those induced by hepatitis $\mathrm{C}$ virus (50), avian influenza viruses (51), rabies virus (52). In addition, the use of phage display systems in this context facilitates screening for ScFvs. HIV gp120-specific ScFvs were selected for use as therapeutic vaccines, and subsequent tests demonstrated excellent efficiency against infection in vitro (53). With regards to the application of T7 phage display to therapeutic vaccines, a T7 phage cDNA library of the infective larval stage of Brugia malayi, the causative agent of lymphatic filariasis, was established. Upon screening of this library with sera from patients, the researchers were able to identify potential vaccine candidates (54). Trichinella spiralis nudix hydrolase protein, which was identified by a T7 phage display cDNA library, led to the generation of local protective immunity in mice (55). The results of these studies indicate that $\mathrm{T} 7$ phage display is promising for the identification of candidate vaccine antigens of infectious agents, and for therapeutic vaccine development more generally.

T7 phage display system for cancer diagnosis and treatment. The traditional approaches to cancer diagnosis and treatment are inefficient, expensive and have low precision. Over the last decade, however, the diagnosis and treatment of cancer has progressed greatly, including the application of novel molecular imaging probes and therapeutic agents (56-58). Furthermore, advances in phage display technology and the development of phage particles have provided further opportunities for the detection and treatment of cancer $(59,60)$. A trackable nanoplatform for positron emission tomography that is based on T7 phage particles was developed as a cancer imaging method (61). This method, therefore, provides the foundations for the construction of cancer-specific theranostic agents and may be applicable to other receptor/ligand systems for theranostic agent construction. A few of peptides that may inhibit tumor growth were generated by utilizing T7 phage display technology (62-64). Using multimodal biopanning of T7 phage-displayed peptides, the site that roxithromycin binds to was identified as the extracellular domain of angiomotin, which is an anti-angiogenic inhibitor angiostatin, leading to the restriction of angiogenesis-dependent tumor growth and metastasis (65). Furthermore, the proteins that interact with sulfoquynovosylacylpropanediol, a novel anticancer agent, were identified using T7 phage display based on HeLa, lung tumor and human umbilical vein endothelial cells (66). Prostate cancer is an important health risk to men, and a novel photothermal therapy employed gold nanoparticles that were formed from genetically modified T7 phages (67). The aforementioned studies highlight the potential of the T7 phage particle and $\mathrm{T} 7$ phage display in cancer diagnosis and treatment.

Additionally, human monoclonal antibodies that are isolated by $\mathrm{T} 7$ phage display libraries may directly detect tumor markers. In breast cancer, research has previously focused on tumor-associated antigens that may be used for detection of cancer. Cancer antigen 15-3 is a traditional biomarker in breast cancer, and its levels are increased in $75 \%$ of advanced-stage patients, while levels are raised in $<10 \%$ of early stage patients (68). Certain results have indicated that the diagnostic accuracy of breast cancer using these serologic biomarkers may be improved by the use of $\mathrm{T} 7$ phage display in combination with autoantibodies (68). Autoantibodies, which exhibit specificity and stability in sera, against tumor-associated antigens may be used for the early detection of cancer in 
noninvasive serological tests (69). A series of representative antigens that led to humoral responses in patients with gastric cancer (GC) were identified by using T7 phage display-based serological analysis of recombinant cDNA expression libraries. Subsequently, phage-antigen microarrays were produced and used to research the autoantibodies produced in patients with GC (69). At present, the early diagnosis of head and neck squamous cell carcinoma (HNSCC) is difficult. However, 5,133 selectively cloned tumor antigens were identified by phage display libraries based on three kinds of diverse HNSCC tissues (70). In addition, to identify valid lung cancer-associated antigens, early screening of patients with lung cancer was performed by diagnostic protein chips derived from a lung cancer T7 phage cDNA library $(71,72)$. As an anticancer drug, methotrexate (MTX) is applied in tumor therapy, and the identification of MTX-binding proteins was performed using T7 phage display (73). Generally, it is seemingly impossible by the naked eyes to count the cancer biomarker miRNAs, but it may be quantified by utilizing the method based on T7 phage display system (74). These studies indicate that the T7 phage display system may aid the development of anticancer drugs and improvement the accuracy of diagnosis.

\section{Concluding remarks and further perspectives}

Phage display technology is a fast, highly efficient and relatively cheap method in bioscience research. The diversity among phage species underlies the differences among the various phage display systems, with commonly used vectors including the M13 and T7 phages. The present review has summarized the advantages of the T7 phage display system over the M13 phage display system. The T7 phage display system has various practical applications in biomedical research, including the investigation of mechanisms of disease, improving the accuracy of cancer diagnosis and the design of potential therapeutic agents and vaccines. A diagram of the principle, process and application of the $\mathrm{T} 7$ phage display system is presented in Fig. 2.

The current review has outlined the various advantages of the T7 phage display system; however, improvements in the technology are still required. The current limitations of $\mathrm{T} 7$ phage display include the following: There are limits to the complexity of peptide display libraries in E. coli, with conversion efficiencies in the region of $10^{7}-10^{8}$, and a peptide library may only have a capacity of $10^{9}$ different sequences; as phage display technology, including T7 phage display, is dependent on the expression of genes within live host cells, it is difficult to effectively express and display toxic molecules; the genes of encoded peptides have certain preferences, whereby the same amino acid for degenerate codon use frequency is not the same, which limits the diversity of the peptide library; amino acid modifications, such as phosphorylation, are restricted by the biology of the host bacterium. Therefore, future studies should focus on improving these limitations to further improve $\mathrm{T} 7$ phage display systems.

\section{Acknowledgements}

The present study was supported by the National Natural Science Foundation of China (grant no. 31370207), Hunan
Provincial Key Laboratory for Special Pathogens Prevention and Control (grant no. 2014-5), Construct Program of the Key Discipline in Hunan Province (grant no. 2011-75) and the Hunan Province Cooperative Innovation Center for Molecular Target New Drug Study (grant no. 2015-351).

\section{References}

1. Smith GP: Filamentous fusion phage: Novel expression vectors that display cloned antigens on the virion surface. Science 228: 1315-1317, 1985.

2. McCafferty J, Griffiths AD, Winter G and Chiswell DJ: Phage antibodies: Filamentous phage displaying antibody variable domains. Nature 348: 552-554, 1990.

3. Barbas CF III, Kang AS, Lerner RA and Benkovic SJ: Assembly of combinatorial antibody libraries on phage surfaces: The gene III site. Proc Natl Acad Sci USA 88: 7978-7982, 1991.

4. Smith GP: Surface presentation of protein epitopes using bacteriophage expression systems. Curr Opin Biotechnol 2: 668-673, 1991.

5. Bass S, Greene R and Wells JA: Hormone phage: An enrichment method for variant proteins with altered binding properties. Proteins 8: 309-314, 1990.

6. Smith GP and Scott JK: Libraries of peptides and proteins displayed on filamentous phage. Methods Enzymol 217: 228-257, 1993.

7. Gao C, Mao S, Kaufmann G, Wirsching P, Lerner RA and Janda KD: A method for the generation of combinatorial antibody libraries using pIX phage display. Proc Natl Acad Sci USA 99: 12612-12616, 2002.

8. Gao C, Mao S, Lo CH, Wirsching P, Lerner RA and Janda KD: Making artificial antibodies: A format for phage display of combinatorial heterodimeric arrays. Proc Natl Acad Sci USA 96: 6025-6030, 1999.

9. Jespers LS, Messens JH, De Keyser A, Eeckhout D, Van den Brande I, Gansemans YG, Lauwereys MJ, Vlasuk GP and Stanssens PE: Surface expression and ligand-based selection of cDNAs fused to filamentous phage gene VI. Biotechnology (N Y) 13: 378-382, 1995.

10. Hufton SE, Moerkerk PT, Meulemans EV, de Bruïne A, Arends JW and Hoogenboom HR: Phage display of cDNA repertoires: The pVI display system and its applications for the selection of immunogenic ligands. J Immunol Methods 231: 39-51, 1999.

11. Zheng Z, Jiang H, Huang Y, Wang J, Qiu L, Hu Z, Ma X and $\mathrm{Lu}$ Y: Screening of an anti-inflammatory peptide from Hydrophis cyanocinctus and analysis of its activities and mechanism in DSS-induced acute colitis. Sci Rep 6: 25672, 2016.

12. Wang Z, Wang D, Chen J, Sela DA and Nugen SR: Development of a novel bacteriophage based biomagnetic separation method as an aid for sensitive detection of viable Escherichia coli. Analyst 141: 1009-1016, 2016.

13. Demerec M and Fano U: Bacteriophage-resistant mutants in escherichia coli. Genetics 30: 119-136, 1945.

14. Sipley J, Stassi D, Dunn J and Goldman E: Analysis of bacteriophage T7 gene 10A and frameshifted 10B proteins. Gene Expr 1: 127-136, 1991.

15. Condron BG, Atkins JF and Gesteland RF: Frameshifting in gene 10 of bacteriophage T7. J Bacteriol 173: 6998-7003, 1991.

16. Molineux IJ: No syringes please, ejection of phage T7 DNA from the virion is enzyme driven. Mol Microbiol 40: 1-8, 2001.

17. Leiman M: Research of effectiveness is a challenge in psychotherapy. Duodecim 120: 2645-2653, 2004 (In Finnish).

18. Chang CY, Kemp P and Molineux IJ: Gp15 and gp16 cooperate in translocating bacteriophage T7 DNA into the infected cell. Virology 398: 176-186, 2010.

19. Lupo D, Leptihn S, Nagler G, Haase M, J Molineux I and Kuhn A: The T7 ejection nanomachine components gp15-gp16 form a spiral ring complex that binds DNA and a lipid membrane. Virology 486: 263-271, 2015.

20. Johns M, George AJ and Ritter MA: In vivo selection of $\mathrm{sFy}$ from phage display libraries. J Immunol Methods 239: 137-151, 2000.

21. Hu CF, Peng XJ, Zhou YY, Tan YP, Li SQ and Zhu YG: Construction of T7 phage display library from the anther of Honglian hybrid line of rice. Yi Chuan 30: 771-775, 2008 (In Chinese). 
22. Paschke M: Phage display systems and their applications. App Microbiol Biotechnol 70: 2-11, 2006.

23. Li W and Caberoy NB: New perspective for phage display as an efficient and versatile technology of functional proteomics. Appl Microbiol Biotechnol 85: 909-919, 2010.

24. Danner S and Belasco JG: T7 phage display: A novel genetic selection system for cloning RNA-binding proteins from cDNA libraries. Proc Natl Acad Sci USA 98: 12954-12959, 2001.

25. Hansen MH, Ostenstad B and Sioud M: Identification of immunogenic antigens using a phage-displayed cDNA library from an invasive ductal breast carcinoma tumour. Int J Oncol 19: 1303-1309, 2001.

26. Larman HB, Zhao Z, Laserson U, Li MZ, Ciccia A, Gakidis MA, Church GM, Kesari S, Leproust EM, Solimini NL and Elledge SJ Autoantigen discovery with a synthetic human peptidome. Nat Biotechnol 29: 535-541, 2011.

27. Talwar H, Rosati R, Li J, Kissner D, Ghosh S, -Madrid FF and Samavati L: Development of a T7 phage display library to detect sarcoidosis and tuberculosis by a panel of novel antigens. EBioMedicine 2: 341-350, 2015.

28. Hashemi H, Pouyanfard S, Bandehpour M, Noroozbabaei Z, Kazemi B, Saelens X and Mokhtari-Azad T: Immunization with M2e-displaying T7 bacteriophage nanoparticles protects against influenza A virus challenge. PLoS One 7: e45765, 2012

29. Gazarian KG, Palacios-Rodríguez Y, Gazarian TG and Huerta L: HIV-1 V3 loop crown epitope-focused mimotope selection by patient serum from random phage display libraries: Implications for the epitope structural features. Mol Immunol 54: 148-156, 2013.

30. Rechkina EA, Denisova GF, Masalova OV, Lideman LF Denisov DA, Lesnova EI, Ataullakhanov RI, Gur'ianova SV and Kushch AA: Epitope mapping of antigenic determinants of hepatitis C virus proteins by phage display. Mol Biol (Mosk) 40 357-368, 2006 (In Russian).

31. Sun EC, Zhao J, Yang T, Liu NH, Geng HW, Qin YL, Wang LF, Bu ZG, Yang YH, Lunt RA, et al: Identification of a conserved JEV serocomplex B-cell epitope by screening a phage-display peptide library with a $\mathrm{mAb}$ generated against West Nile virus capsid protein. Virol J 8: 100, 2011.

32. Beghetto E, De Paolis F, Montagnani F, Cellesi C and Gargano N Discovery of new Mycoplasma pneumoniae antigens by use of a whole-genome lambda display library. Microbes Infect 11: 66-73, 2009.

33. Beghetto E, Gargano N, Ricci S, Garufi G, Peppoloni S, Montagnani F, Oggioni M, Pozzi G and Felici F: Discovery of nove streptococcus pneumoniae antigens by screening a whole-genome lambda-display library. FEMS Microbiol Lett 262: 14-21, 2006.

34. Li Y, Ning YS, Wang YD, Hong YH, Luo J, Dong WQ and Li M: Production of mouse monoclonal antibodies against Helicobacter pylori Lpp20 and mapping the antigenic epitope by phage display library. J Immunol Methods 325: 1-8, 2007.

35. Fan $\mathrm{H}$, Wang $\mathrm{Y}$, Tang $\mathrm{F}$ and Lu C: Determination of the mimic epitope of the M-like protein adhesin in swine Streptococcus equi subsp. Zooepidemicus. BMC Microbiol 8: 170, 2008.

36. Wong CL, Sieo CC and Tan WS: Display of the VP1 epitope of foot-and-mouth disease virus on bacteriophage T7 and its application in diagnosis. J Virol Methods 193: 611-619, 2013.

37. Pouyanfard S, Bamdad T, Hashemi H, Bandehpour $M$ and Kazemi B: Induction of protective anti-CTL epitope responses against HER-2-positive breast cancer based on multivalent $\mathrm{T} 7$ phage nanoparticles. PLoS One 7: e49539, 2012

38. Yang J, Fuller PJ, Morgan J, Shibata H, McDonnell DP, Clyne CD and Young MJ: Use of phage display to identify novel mineralocorticoid receptor-interacting proteins. Mol Endocrinol 28: 1571-1584, 2014

39. Gao W, He W, Zhao K, Lu H, Ren W, Du C, Chen K, Lan Y, Song D and Gao F: Identification of NCAM that interacts with the PHE-CoV spike protein. Virol J 7: 254, 2010.

40. Caberoy NB, Zhou Y, Jiang X, Alvarado G and Li W: Efficient identification of tubby-binding proteins by an improved system of T7 phage display. J Mol Recognit 23: 74-83, 2010.

41. Blessing AM, Ganesan S, Rajapakshe K, Ying Sung Y, Reddy Bollu L, Shi Y, Cheung E, Coarfa C, Chang JT, McDonnell DP and Frigo DE: Identification of a Novel Coregulator, SH3YL1, that interacts with the androgen receptor n-terminus. Mol Endocrinol 29: 1426-1439, 2015

42. Takami M, Takakusagi Y, Kuramochi K, Tsukuda S, Aoki S, Morohashi K, Ohta K, Kobayashi S, Sakaguchi K and Sugawara F: A screening of a library of T7 phage-displayed peptide identifies E2F-4 as an etoposide-binding protein. Molecules 16: 4278-4294, 2011.
43. Ren HJ, Liu RD, Wang ZQ and Cui J: Construction and use of a Trichinella spiralis phage display library to identify the interactions between parasite and host enterocytes. Parasitol Res 112: $1857-1863,2013$

44. Lauterbach SB, Lanzillotti R and Coetzer TL: Construction and use of Plasmodium falciparum phage display libraries to identify host parasite interactions. Malar J 2: 47, 2003.

45. Cardona-Correa A and Rios-Velazquez C: Profiling lethal factor interacting proteins from human stomach using T7 phage display screening. Mol Med Rep 13: 3797-3804, 2016.

46. Fang L, Xu Z, Wang GS, Ji FY, Mei CX, Liu J and Wu GM: Directed evolution of an LBP/CD14 inhibitory peptide and its anti-endotoxin activity. PLoS One 9: e101406, 2014.

47. Silman NJ: World influenza congress Europe 2009. Expert Rev Vaccines 9: 273-275, 2010.

48. Tan GH, Yusoff K, Seow HF and Tan WS: Antigenicity and immunogenicity of the immunodominant region of hepatitis B surface antigen displayed on bacteriophage T7. J Med Virol 77: 475-480, 2005

49. Lv Q, Xing S, Gong P, Chang L, Bian Z, Wang L, Zhang X and Li J: A $78 \mathrm{kDa}$ host cell invasion protein of Neospora caninum as a potential vaccine candidate. Exp Parasitol 148: 56-65, 2015.

50. Lun YZ, Cheng J, Zhong YW, Yu ZG, Wang Q, Wang F and Feng J: Cloning, expression and identification by immunohistochemistry of humanized single-chain variable fragment antibody against hepatitis $\mathrm{C}$ virus core protein. Pol J Microbiol 60: 13-17, 2011.

51. Gabbard J, Velappan N, Di Niro R, Schmidt J, Jones CA, Tompkins SM and Bradbury AR: A humanized anti-M2 scFv shows protective in vitro activity against influenza. Protein Eng Des Sel 22: 189-198, 2009.

52. Aavula SM, Nimmagadda SV, Biradhar N, Sula S, Chandran D, Lingala R and Villuppanoor SA: Generation and characterization of an $\mathrm{scFv}$ directed against Site II of rabies glycoprotein. Biotechnol Res Int 2011: 652147, 2011.

53. Abdel-Motal UM, Sarkis PT, Han T, Pudney J, Anderson DJ, Zhu Q and Marasco WA: Anti-gp120 minibody gene transfer to female genital epithelial cells protects against HIV-1 virus challenge in vitro. PLoS One 6: e26473, 2011.

54. Gnanasekar M, Rao KV, He YX, Mishra PK, Nutman TB, Kaliraj $\mathrm{P}$ and Ramaswamy K: Novel phage display-based subtractive screening to identify vaccine candidates of Brugia malayi. Infect Immun 72: 4707-4715, 2004.

55. Long SR, Wang ZQ, Jiang P, Liu RD, Qi X, Liu P, Ren HJ, Shi HN and Cui J: Characterization and functional analysis of Trichinella spiralis Nudix hydrolase. Exp Parasitol 159: 264-273, 2015.

56. Conde J, Doria G and Baptista P: Noble metal nanoparticles applications in cancer. J Drug Deliv 2012: 751075, 2012.

57. Mitsunaga M, Ogawa M, Kosaka N, Rosenblum LT, Choyke PL and Kobayashi H: Cancer cell-selective in vivo near infrared photoimmunotherapy targeting specific membrane molecules. Nat Med 17: 1685-1691, 2011.

58. Luo S, Zhang E, Su Y, Cheng T and Shi C: A review of NIR dyes in cancer targeting and imaging. Biomaterials 32: 7127-7138, 2011.

59. Allegra A, Penna G, Alonci A, Rizzo V, Russo S and Musolino C: Nanoparticles in oncology: The new theragnostic molecules. Anticancer Agents Med Chem 11: 669-686, 2011.

60. Shubayev VI, Pisanic TR II and Jin S: Magnetic nanoparticles for theragnostics. Adv Drug Deliv Rev 61: 467-477, 2009.

61. Li Z, Jin Q, Huang C, Dasa S, Chen L, Yap LP, Liu S, Cai H, Park R and Conti PS: Trackable and targeted phage as positron emission tomography (PET) agent for cancer imaging. Theranostics 1: 371-380, 2011.

62. Jemal A, Siegel R, Ward E, Murray T, Xu J and Thun MJ: Cancer statistics, 2007. CA Cancer J Clin 57: 43-66, 2007.

63. Koolpe M, Dail M and Pasquale EB: An ephrin mimetic peptide that selectively targets the EphA2 receptor. J Biol Chem 277: 46974-46979, 2002 .

64. Sakamoto K, Kamada Y, Sameshima T, Yaguchi M, Niida A, Sasaki S, Miwa M, Ohkubo S, Sakamoto JI, Kamaura M, et al: $\mathrm{K}$-Ras(G12D)-selective inhibitory peptides generated by random peptide T7 phage display technology. Biochem Biophys Res Commun 484: 605-611, 2017.

65. Takakusagi K, Takakusagi Y, Suzuki T, Toizaki A, Suzuki A, Kawakatsu Y, Watanabe M, Saito Y, Fukuda R, Nakazaki A, et al: Multimodal biopanning of T7 phage-displayed peptides reveals angiomotin as a potential receptor of the anti-angiogenic macrolide Roxithromycin. Eur J Med Chem 90: 809-821, 2015. 
66. Izaguirre-Carbonell J, Kawakubo H, Murata H, Tanabe A, Takeuchi T, Kusayanagi T, Tsukuda S, Hirakawa T, Iwabata K, Kanai Y, et al: Novel anticancer agent, SQAP, binds to focal adhesion kinase and modulates its activity. Sci Rep 5: 15136, 2015.

67. Oh MH, Yu JH, Kim I and Nam YS: Genetically programmed clusters of gold nanoparticles for cancer cell-targeted photothermal therapy. ACS Appl Mater Interfaces 7: 22578-22586, 2015.

68. Dong X, Yang M, Sun H, Lü J, Zheng Z, Li Z and Zhong L: Combined measurement of CA 15-3 with novel autoantibodies improves diagnostic accuracy for breast cancer. Onco Targets Ther 6: 273-279, 2013.

69. Zayakin P, Ancāns G, Siliņa K, Meistere I, Kalniņa Z, Andrejeva D, Endzeliņš E, Ivanova L, Pismennaja A, Ruskule A, et al: Tumor-associated autoantibody signature for the early detection of gastric cancer. Int J Cancer 132: 137-147, 2013.

70. Lin HS, Talwar HS, Tarca AL, Ionan A, Chatterjee M, Ye B, Wojciechowski J, Mohapatra S, Basson MD, Yoo GH, et al: Autoantibody approach for serum-based detection of head and neck cancer. Cancer Epidemiol Biomarkers Prev 16: 2396-2405, 2007.
71. Li HM, Guo K, Yu Z, Feng R and Xu P: Diagnostic value of protein chips constructed by lung-cancer-associated markers selected by the T7 phage display library. Thorac Cancer 6: 469-474, 2015.

72. Yuan N, Xin GH, Zuo XX, Huang SK, Wang Y, Hou L, Qin TJ and Zhao XH: Combination of phage display and SEREX for screening early lung cancer associated antigens. Zhejiang Da Xue Xue Bao Yi Xue Ban 43: 388-396, 2014 (In Chinese).

73. Kuroiwa Y, Takakusagi Y, Kusayanagi T, Kuramochi K, Imai T, Hirayama T, Ito I, Yoshida M, Sakaguchi K and Sugawara F: Identification and characterization of the direct interaction between methotrexate (MTX) and high-mobility group box 1 (HMGB1) protein. PLoS One 8: e63073, 2013.

74. Zhou X, Cao P, Zhu Y, Lu W, Gu N and Mao C: Phage-mediated counting by the naked eye of miRNA molecules at attomolar concentrations in a Petri dish. Nat Mater 14: 1058-1064, 2015. 